\title{
Delayed two-stage breast reconstruction with implants: The authors' recent experience
}

\author{
Jan Rykała MD PhD, Paweł Szychta MD, Julia Kruk-Jeromin Professor
}

J Rykała, P Szychta, J Kruk-Jeromin. Delayed two-stage breast reconstruction with implants: The authors' recent experience. Can J Plast Surg 2011;19(3):88-92.

BACKGROUND: Presently, breast cancer detection is delayed in Poland and, thus, the only other option for patients is amputation and breast reconstruction (immediate or delayed). Reconstructive methods are based on using the patient's own tissue (pedicled or free myocutaneous flaps) or implants (a tissue expander, which is later exchanged for a prosthesis or an expandable implant).

OBJECTIVE: To evaluate the aesthetic results of a delayed two-stage breast reconstruction with the use of implants (expander and prosthesis) in patients who have previously undergone cancer-related mastectomy.

METHODS: From 2006 to 2009, 54 patients (34 to 65 years of age) underwent reconstruction at least one year after their mastectomy and adjuvant chemotherapy; three women also received $\mathrm{x}$-ray therapy. All women underwent a two-stage treatment with a tissue expander, which was later exchanged for a prosthesis.

RESULTS: Outcomes of the surgery (evaluated by the physician and the patient at least six months after all stages of reconstruction) were found to be very good in 42 patients and good in 12 patients. After amputation and $\mathrm{x}$-ray therapy in two cases, a fistula developed, which necessitated implant removal.

CONCLUSIONS: After amputation, breast reconstruction with implants (expander and prosthesis) provides good aesthetic results. The method is mildly burdening to the patient and does not cause severe scarring. Symmetrization of the second breast is often recommended; however, the cost is not covered by the national health system. In principle, earlier x-ray therapy disqualifies the application of implants. Dividing reconstruction into two stages (expander and prosthesis) allows for possible correction of prosthesis placement.

Key Words: Breast implant; Breast reconstruction; Delayed; Prosthesis; Tissue expander; Two stage

Dresently, more life-saving operations are being performed worldwide for breast cancer than amputations. In Poland, the detection of cancer continues to be delayed, so the only other option for patients is amputation and reconstruction of the breast (immediate or delayed) (1). The methods of restoration are based on the use of the patient's own tissue (pedicled or free myocutaneous flaps) or implants (a tissue expander, which is later exchanged for a prosthesis or an expandable implant). Currently, breast reconstruction (immediate or deferred) is considered to be an integral part of breast cancer treatment because it improves quality of life (2-6). According to some surgeons, performing the reconstructive operation at a later time after mastectomy yields a better aesthetic result $(4,6)$. Compared with patients undergoing breast amputation and immediate reconstruction, individuals subjected to reconstructive surgery at a later time report that they have a better image of their body and experience greater satisfaction because they can compare the local condition pre- and postreconstruction (5). Indications for delayed breast reconstructive surgery are the following: planning adjuvant oncological therapy (mainly radiotherapy), contraindications for prolonged general anaesthesia and/or strong patient

\section{La reconstruction mammaire tardive en deux étapes à l'aide d'implants : l'expérience récente des auteurs}

HISTORIQUE : À l'heure actuelle, le dépistage du cancer du sein est retardé en Pologne. Par conséquent, l'amputation et la reconstruction du sein (immédiate ou tardive) constituent la seule autre possibilité pour les patientes. Les méthodes reconstructives se fondent sur l'utilisation des propres tissus des patients (lambeaux pédiculés ou lambeaux libres myocutanés) ou sur des implants (expanseur tissulaire ensuite remplacé par une prothèse ou un implant extensible).

OBJECTIF : Évaluer les résultats esthétiques d'une reconstruction mammaire tardive en deux étapes avec des implants (extenseur et prothèse) chez des patientes ayant subi une mastectomie en raison d'un cancer. MÉTHODOLOGIE : De 2006 à 2009, 54 patientes (de 34 à 65 ans) ont subi une reconstruction au moins un an après avoir été traitées par mastectomie et chimiothérapie adjuvante. Trois femmes ont également été sous radiothérapie. Toutes les femmes ont été traitées en deux étapes à l'aide d'un expanseur tissulaire, qui a ensuite été remplacé par une prothèse.

RÉSULTATS : Les résultats de la chirurgie (évalués par le médecin et le patient au moins six mois après toutes les étapes de reconstruction) se sont révélés très bons chez 42 patientes et bons chez 12 patientes. Après l'amputation et la radiothérapie dans deux cas, une fistule s'est formée et a exigé l'exérèse de l'implant.

CONCLUSIONS : Après l'amputation, la reconstruction mammaire à l'aide d'implants (expanseur et prothèse) donne des résultats esthétiques satisfaisants. La méthode constitue un fardeau bénin pour la patiente et ne provoque pas de cicatrices importantes. La symétrisation du deuxième sein est souvent recommandée, mais les coûts ne sont pas remboursés par le système de santé national. En principe, une radiothérapie antérieure disqualifie l'installation d'implants. Le fait de diviser la reconstruction en deux étapes (expanseur et prothèse) permet de corriger l'emplacement de la prothèse, au besoin.

motivation after treatment completion for cancer (3). Due to numerous advantages, more than $80 \%$ of breast reconstructive surgeries are performed as delayed procedures in the United States (2).

Tissue expansion enabled the development of alternative methods for breast reconstruction. Application of a tissue expander and implant to restore the breast mound provided very good results in selected patients; advantages of this method include the following: ease of implementation, no additional scars, elimination of the possibility of complications in the donor area, as well as shorter operation time, hospitalization and convalescence (7). Long-term aesthetic outcomes of certain methods of breast reconstruction using the patient's own tissues (such as the transverse rectus abdominis myocutaneous flap and the latissimus dorsi flap) may be unsatisfactory due to postoperative resorption of fat within the flap used for reconstruction. Microsurgical techniques of free flap transfer, especially based on perforators (eg, the deep inferior epigastric artery perforator flap and the superficial inferior epigastric artery), overcome fat resorption problems $(8,9)$. Two-stage reconstruction with implants (expander and prosthesis) compared with a one-stage procedure (expandable implant) yields more predictable

Plastic, Reconstructive and Aesthetic Surgery Department, Medical University of Lodz, Poland

Correspondence: Dr Pawet Szychta, Plastic, Reconstructive and Aesthetic Surgery Department, Medical University of Lodz,

Ul. Kopcinskiego 22, 90-153 Lodz, Poland. Telephone 48-42-677-67-42, fax 48-42-677-67-49, e-mail szychta@yahoo.pl 

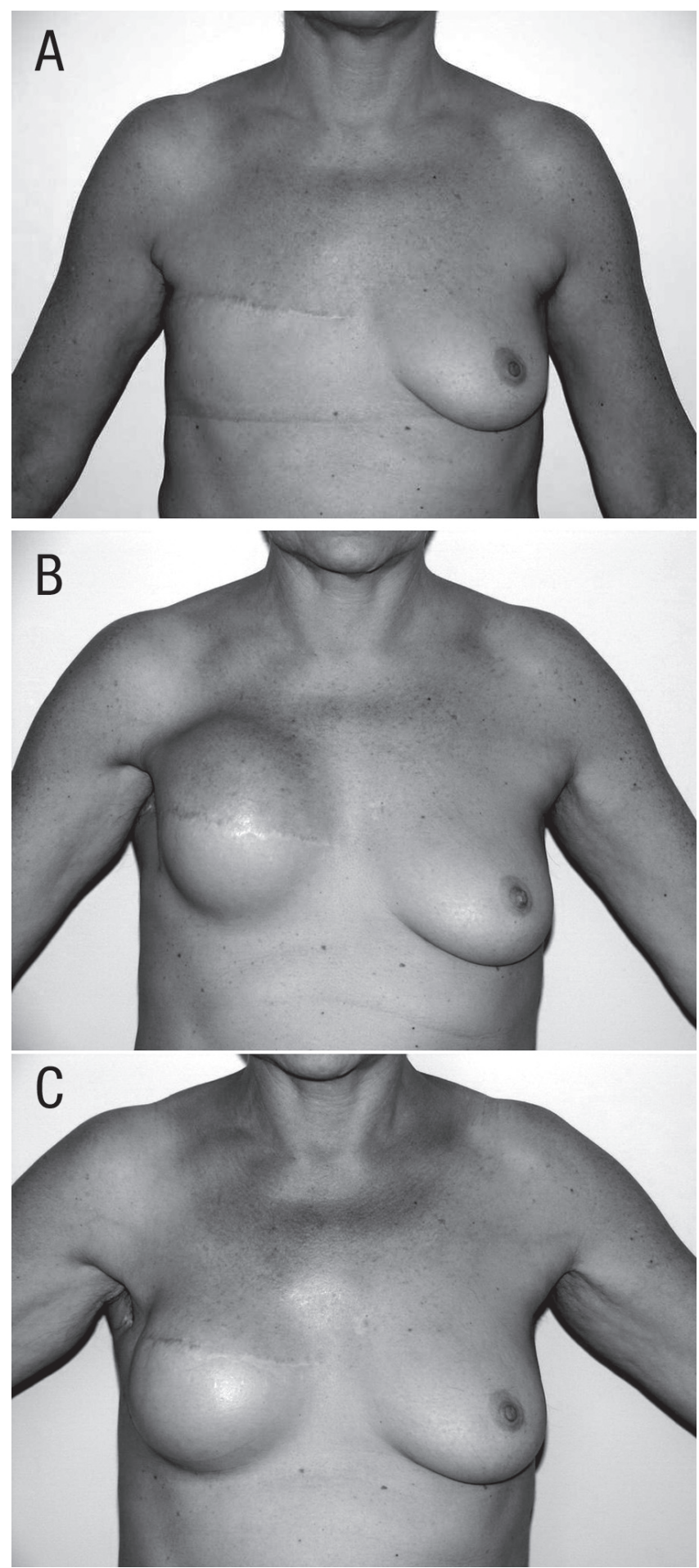

Figure 1) A Patient after amputation of the right breast. B After the first stage of reconstruction with the expander. Significant breast asymmetry may be corrected at the time of prosthesis implantation. C Postreconstruction: Symmetrical breasts

results because the position of the implant can be corrected during the second operation $(10,11)$. This method is preferred by most patients and, therefore, is more common (10-13). However, the majority of patients in Poland avoid using their own tissues for reconstruction. It is worth noting that a lack of adequate skills in breast reconstruction surgery can lead to serious complications and poor results (12).

The aim of the present study was to evaluate the aesthetic results of a delayed two-stage breast reconstruction with the use of implants
TABLE 1

Treatment schemes in patients undergoing two-stage breast reconstruction with expander and implant

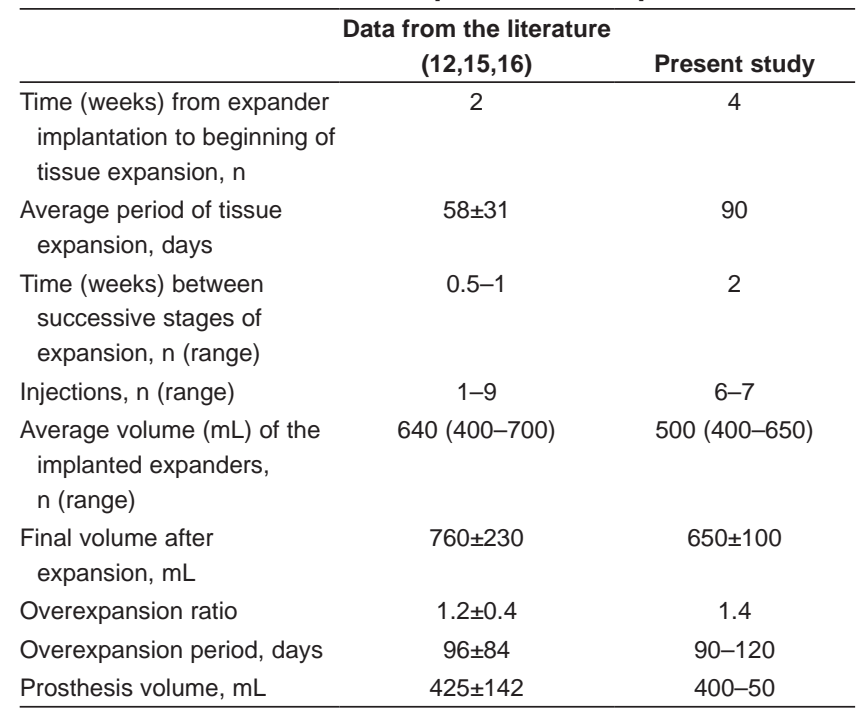

Data presented as mean \pm SD unless otherwise indicated

(expander and prosthesis) in patients who had undergone mastectomy due to cancer.

\section{PATIENTS AND METHODS}

Between 2006 and 2009, in the Plastic, Reconstructive and Aesthetic Surgery Department of the Medical University of Lodz (Lodz, Poland), 54 patients ( 34 to 65 years of age) qualified for breast reconstruction; all patients recovered from radical breast amputation (Madden) for T2 advanced cancer and adjuvant therapy (chemotherapy), which was performed at least one year earlier (Figure 1). The study group also included an additional three patients who previously underwent $\mathrm{x}$-ray therapy. All patients were qualified for delayed reconstructive treatment at least one year after completion of oncological treatment, which had a positive impact on the quality of scar tissue and the operated area. In all cases, the treatment was given in two stages - first, the expander was implanted and was later exchanged for a prosthesis.

Before the two-stage reconstruction, the exact size of the expander was determined by measurements of the existing second breast, which was used as a model. Before surgery, a prophylactic antibiotic was administered. An incision was made at the mastectomy scar. The pectoralis major was separated along its fibres and a pocket was produced by blunt preparation of the pectoralis major and serratus anterior muscles, and the upper fascia of the muscle fibres (obliquus externus and rectus). A smooth, round expander (Eurosilicone SAS, France) was implanted into the generated space. A port to the expander was placed in a subcutaneous pocket in the middle axillary line above the bra strap. The expander was introduced intraoperatively and filled with approximately $60 \mathrm{~mL}$ of saline, which allowed the closure of the wound without tension. The suction drain was maintained for one day. In fewer than 10 patients, antibiotic therapy was continued through to suture removal (seven to 10 days).

Tissue expansion was started after four weeks. The gradual increase of the expander volume was performed every 14 days; expansion and adaptation of tissues lasted an average of six months. The period from the end of stretching of the operated area to the second stage of reconstruction totalled an average of three months, and resulted in a sufficiently large space for the final prosthesis. In all patients, the expander was exchanged for a round gel-textured Eurosilicone prosthesis, which was smaller $(100 \mathrm{~mL})$ than the expander (Table 1). The drain was not used during the second operation because of lack of indications in all cases; however, antibiotic therapy was continued. The patients were 
advised to massage the soft tissues covering the implant, to wear flexible bras and to avoid injuries. All patients were informed about the availability of breast symmetrization, but it was performed in only two cases due to lack of funding for this procedure by the national health system. All patients were qualified to undergo restoration of the nipple-areola complex after approximately six months postimplantation. During the time of the study, the surgery was performed in four women; other patients considered the possibility of surgical treatment at a later date. However, some patients reported a significant improvement in quality of life and wished to avoid any additional surgeries.

Additionally, in nine patients, the size of the expander/implant was preoperatively selected with a three-dimensional scanner that aided in achieving promising aesthetic results. Postoperatively, the shape and asymmetry of both breasts after unilateral breast reconstruction was also assessed with three-dimensional imaging. Applicability of threedimensional imaging in preoperative planning for breast reconstruction with implants is the subject of planned studies and, presently, the authors have limited experience with this innovative method for anthropometric assessment.

\section{RESULTS}

The results of reconstructive treatment were evaluated after the first stage, when the expander was implanted; and at the second stage, after the exchange of the expander for the prosthesis. General anaesthesia and surgery were well tolerated in 54 cases. Two patients experienced severe pain in the operated area, as well as nausea and vomiting after awakening from the anaesthetic, which temporarily adversely affected their overall condition. The vast majority of patients (49 women) reported no issues regarding the proposed procedures and the tissue expansion. In four patients, there was a shift of the prosthesis toward the clavicle or axilla, resulting in an asymmetrical position of the submammary fold. Two patients who underwent $\mathrm{x}$-ray therapies after the amputation developed fistulas during the first phase of reconstructive treatment (expander implantation); thus, the implant had to be removed. One patient developed bronchitis after partial filling of the expander's volume and inflammation at the site of the implant. The condition was managed by prompt conservative treatment and, consequently, removal of the implant was avoided. As a result, the outcome after the first stage of breast reconstruction was assessed as good in 48 patients, unsatisfactory in four patients and poor in two patients.

The second phase of reconstruction - the exchange of the expander for the prosthesis - was performed six months (average) after the first surgery and was also performed under general anaesthesia. Subjective pain perception was significantly lower than after the first surgery.

In 42 patients, the result of the two-stage breast reconstruction (assessed by a physician and the patient at least six months after reconstruction) was considered to be very good. The result of the reconstruction was assessed as very good when the tissues covering the prosthesis were soft, the breasts showed relative symmetry and the submammary folds were located on the same level. Most patients with a very good reconstruction result were of slim build and had small to medium breast sizes.

In 12 patients, the results were rated as good. These were the cases in whom a slight distortion of the reconstructed breast, caused by fibrosis, occurred as a result of tissue healing. Good results were also achieved in individuals who lost or gained weight in the postoperative period, giving the image of slight breast asymmetry, but also in obese patients with large and ptotic contralateral breasts. Of these, only two patients underwent mastopexy of the healthy breast due to the cost of the procedure.

In the present study, no other operational failures resulting from both the general condition of patients and the method of reconstructive surgery were observed. Capsular contracture was never above 1 on the Baker classification scale.

In the postoperative period, one patient died tragically in a car accident. Seven patients did not report for the control checkup in the following 18 months. The other 48 women were under constant oncological surveillance. In the period analyzed (from six to 30 months), there were no signs of tumour recurrence or distant metastases in additional studies of any case. Most patients completed the therapy after volume restoration of the lost breast, but some raised questions about the continuation of treatment, specifically symmetrization of the contralateral breast and reconstruction of the nipple-areola complex.

\section{DISCUSSION}

Good results after immediate reconstructive procedures can be obtained only in some patients (ie, young women with small breasts or in patients with large breasts treated with sparing mastectomy and subsequent symmetrization of the opposite area of the body [14]). Temporary use of the expander, as in our study, facilitates the expansion of tissues, which significantly improves the long-term treatment results. In addition, during the second phase of reconstruction, it is possible to achieve symmetry of both pectoral areas and to improve the level of the submammary fold. To obtain a good aesthetic result, treatment schemes in patients subjected to two-stage breast reconstruction with expander and implant were created (Table 1) $(12,15,16)$.

Few reports in the available literature have evaluated the aesthetic aspect of two-stage breast reconstruction with the expander/implant. Cordeiro and McCarthy (17) obtained good to excellent aesthetic results in $90 \%$ of the 315 women studied after a mean follow-up period of three years. In our study, $75 \%$ of women achieved very good reconstructive treatment outcomes after six months. Nava et al (18) reported breast restoration results that were consistent with the above studies. Due to the use of anatomical expanders/implants, Strock (12) achieved a very good result in all examined cases evaluated by the surgeon and patients. A good breast reconstruction result can be obtained through the use of excessive expansion to achieve complete ptosis of the reconstructed breast (12). In our study, the mean volume of the implanted expander was $500 \mathrm{~mL}$ ( $400 \mathrm{~mL}$ to $650 \mathrm{~mL}$ ). The first $60 \mathrm{~mL}$ of solution was filled during the surgery and the second injection for expansion was administered after the wound was considered to be healed, which contributed to a thin postoperative scar.

Until recently, it was believed that the use of an anatomically shaped prosthesis provided better aesthetic outcomes (19). However, the cost of the implant is higher and it is not financed by the national health system in several countries, including Poland. Recently, Gahm et al (20) found no differences in aesthetic results between bilateral breast reconstruction with the use of anatomically shaped implants and round implants. In most cases, we achieved good to very good aesthetic results after breast reconstruction with round prostheses. However, round implants or expanders often cause excessive upper pole fullness of the reconstructed breast, which in the present study was observed in four women.

Some patients reported that the disadvantage of using a tissue expander and then switching to a final prosthesis was the discomfort associated with the need to undergo two separate operations. This method of reconstruction is frequently chosen because of good aesthetic results and fewer postoperative complications (12).

During delayed breast reconstruction, patients are psychologically better prepared to assess the result of the operation $(4,6)$. Roth et al (6) observed a better quality of life in patients who underwent surgery a few months after mastectomy compared with those in whom amputation was followed by immediate reconstruction. The following disorders appear (although to a lesser severity) in the former group: disturbed mood, anxiety, affective disorder, obsessive-compulsive traits, problems at work and everyday activities. However, prolongation of the planned breast reconstruction more than one year after mastectomy deteriorates the patient's mental condition, which affects the decision to reconstruct (6).

The occurrence of complications after surgery is an important element of dissatisfaction in patients after breast reconstruction using expander/prosthesis implants $(4,6)$. Complications may occur in $43 \%$ of patients and include the formation of a hematoma, wound infection, prolonged wound healing, wound dehiscence, skin necrosis, 
asymmetry of the pectoral area, displacement of prostheses, thinning of the skin, capsular contracture and rupture of implants $(15,20,21)$. According to the available literature (15), patients undergo an average of three operations during reconstruction with implants due to the need for surgical treatment of complications.

Collis and Sharpe (15) described the incidence of early complications after breast reconstruction using implants in 197 patients. They did not observe hematoma following implantation of a smooth expander; after conversion to prosthesis, hematoma occurred in $0.8 \%$ of women. Damage to the temporary implant was observed in $4 \%$ of patients; skin necrosis associated with tissue expansion occurred in $1.5 \%$ of patients, of which two of three cases were previously treated with radiotherapy. Wound infection was treated in $6.2 \%$ of patients, and the authors observed total failure of breast reconstruction in $3 \%$ of patients (15). In our study, both in the first and second stage of reconstruction, there were no hematomas. In 15 patients, we observed bruises after removal of the port to fill the expander. However, this did not affect wound healing, the location of the prosthesis or the final result.

The most common distant complication after implantation of the expander/prosthesis is contracture of the fibroblastic capsule that forms around the prosthesis, which leads to deterioration of the aesthetic result. Tissue expansion before implantation of the prosthesis reduces the risk of its occurrence (21). Contracture mostly occurs during the first 18 months after operation and is present after two years in at least $15 \%$ of patients $(15,22)$. In severe cases of capsular contracture, a capsulotomy is necessary. Some authors consider the appearance of the capsule to be mainly related to the type of implant and not to the speed of tissue expansion, intensity or duration of overexpansion (15). Application of textured implants likely reduces the incidence of complications including capsular contracture (19). There is also a lower risk of prosthesis displacement due to better tissue adhesion. The most frequent complication, which is contracture of the formed fibroblastic capsule around the prosthesis leading to the deterioration of the aesthetic result, was not observed in our patients, despite the fact that we inserted smooth implants.

The risk of prosthesis rupture increases eight years after its implantation and is not usually associated with trauma. In their study, Collis and Sharpe (15) reported that 50\% of cases required implant removal fewer than two years after implantation. Coexisting symptoms of implant rupture include pain, breast deformation and/or changes in the skin. Prosthesis rupture can be identified by ultrasound. The period of tissue expansion, degree of overexpansion and breast volume are not determinants of implant failure $(15,21,23)$. Our observations relate to 48 patients with a maximum follow-up period of three years, and we have not observed any prosthesis rupture.

Infection is often a cause of implant removal. Francis et al (24) treated $16.5 \%$ of patients with antibiotics who underwent prosthesis implantation with a median time to diagnosis of 6.5 weeks (24). Independent risk factors for infection in tissue expander breast reconstruction included breast size larger than a $\mathrm{C}$ cup, previous irradiation, repeated implant and delayed reconstruction. However, we did not observe signs of infection during the follow-up period.

The risk of complications is much lower after delayed breast reconstruction compared with immediate operation $(2,5)$. Therefore, breat amputation and immediate expander insertion do not always reduce the total number of surgical procedures due to high incidence of complications (5). Simultaneous implantation of the expander with mastectomy and immediate breast construction with implants may be associated with a high risk of skin necrosis and prolonged wound healing (13). Contant et al (25) evaluated the occurrence of such complications in $40 \%$ of cases, and the need to remove the prosthesis appeared in $10 \%$ of cases within three years after surgery. In another study (5), capsular contracture occurred in $40 \%$ of cases after immediate reconstruction (167 patients) compared with $17 \%$ after delayed surgery (167 women). Giacalone et al (26) also described a higher incidence of adverse events after immediately restoring the breast mound.
Cigarette smoking is considered to be a major risk factor for wound healing. Goodwin et al (27) reported a significantly higher percentage of complications among 515 patients undergoing twostage reconstruction with expander/implants (including wound infection, skin necrosis and adverse outcome) among smokers (current or former) compared with nonsmoking patients. In our study, we did not observe negative effects of cigarette smoking on the occurrence of the aforementioned complications, although seven women smoked approximately five cigarettes a day during reconstructive treatment.

The range of indications for radiotherapy in the treatment of breast cancer has significantly expanded since the 1990s due to its positive effect on patient survival rates $(28,29)$. In accordance with the American Society for Clinical Oncology guidelines, previous radiotherapy must be taken into account in patients undergoing mastectomy (30). Irradiation causes complex changes in the tissues, such as interstitial fibrosis, thickening of the arteriole walls and their obliteration, which results in increased incidence of capsular contracture, the emergence of seroma, infection and/or impaired wound healing (31). Undergoing radiotherapy both before and after breast reconstruction has a negative impact on its outcome, which is important when considering the optimum timing of breast restoration $(2,32)$. The vast majority of reports indicated the increased risk of complications in patients after reconstruction with implants after previous irradiation ( $51 \%$ to $68 \%$ ) compared with patients who did not undergo radiotherapy ( $10 \%$ to $31 \%$ ) (33). It is generally acknowledged that $\mathrm{x}$-ray therapy may have an adverse effect on the final outcome of the reconstruction, even when performed several months before tissue expansion (34). In our study, in two patients who underwent teleradiotherapy immediately after the amputation, a fistula appeared during the first phase of reconstructive treatment (implantation of the expander), and the implant had to be removed. It should be noted that both patients were informed before treatment about the existing risks of using implants; nevertheless, they decided to undergo the operation.

Because of these reservations, it was believed, until recently, that breast reconstruction with expander/prosthesis was completely contraindicated in patients previously treated with radiotherapy (31). Parsa et al (35) compared the results of the operation in an irradiated area with the opposite side of the body in 27 patients undergoing bilateral mastectomy, followed by unilateral radiotherapy and bilateral delayed reconstruction with expander/prosthesis. The authors showed that the results of the surgery were comparable with the contralateral, nonirradiated side of the body in patients in whom changes in the skin after radiotherapy were characterized by low or moderate intensity and there was no firming of tissues. Currently, reports suggest that patients who undergo radiation therapy may be eligible for implantation of the expander/prosthesis, taking into account the contraindications of the local condition of the operated area $(31,35)$. In patients with severe changes in local skin, reconstruction with their own tissues should be considered. However, there are reports suggesting that radiotherapy after mastectomy also adversely affects the results of reconstruction using these methods of restoring the breast mound $(3,36)$.

\section{CONCLUSIONS}

1. Breast reconstruction with implants yields good aesthetic results. 2. Dividing the reconstruction into two stages (the expander and prosthesis) allows for possible correction of implant positioning.

3. X-ray adjuvant therapy after mastectomy resulted in high rates of complications. Therefore, in these cases, breast reconstruction with the patient's own tissues should be planned.

4. Only a small number of patients decided to restore the nipple-areola complex immediately after breast reconstruction.

5. Mastopexy of the healthy breast is not widely implemented because the cost is not covered by the national health care system. 


\section{REFERENCES}

1. Towpik E. [Operacje odtwórcze piersi: 15 lat doswiadczen Centrum Onkologii w Warszawie]. Nowotwory 2000;50:529-35.

2. Chevray PM. Timing of breast reconstruction: Immediate versus delayed. Cancer J 2008;14:223-9.

3. Jassem J, Krzakowski M, Olszewski W. [Rak piersi. Zalecenia diagnostyczno-terapeutyczne Polskiej Unii Onkologii]. Nowotwory 2003;53:300-24.

4. Nicholson RM, Leinster S, Sassoon EM. A comparison of the cosmetic and psychological outcome of breast reconstruction, breast conserving surgery and mastectomy without reconstruction. Breast 2007;16:396-410.

5. Sullivan SR, Fletcher DR, Isom CD, Isik FF. True incidence of all complications following immediate and delayed breast reconstruction. Plast Reconstr Surg 2008;122:19-28.

6. Roth RS, Lowery JC, Davis J, Wilkins EG. Quality of life and affective distress in women seeking immediate versus delayed breast reconstruction after mastectomy for breast cancer.

Plast Reconstr Surg 2005;116:993-1002.

7. Mathes SJ, Massey M. Postmastectomy reconstruction: Expander-implant technique. In: Mathes SJ, ed. Plastic Surgery. London: Saunders Elsevier 2006;6:875-971.

8. Neligan PC, Morris SF. Perforator flaps for breast reconstruction. In: Mathes SJ, ed. Plastic Surgery. London: Saunders-Elsevier 2006;6:1039-52.

9. Elliot LF, Bergey P. Postmastectomy reconstruction. Alternative free flaps. In: Mathes SJ, ed. Plastic Surgery. London: Saunders Elsevier 2006;6:1053-65.

10. Loustau HD, Mayer HF, Sarrabayrouse M. Pocket work for optimising outcomes in prosthetic breast reconstruction. J Plast Reconstr Aesthet Surg 2009;62:626-32.

11. Mesbahi AN, McCarthy CM, Disa JJ. Breast reconstruction with prosthetic implants. Cancer J 2008;14:230-5.

12. Strock LL. Two-stage expander implant reconstruction: Recent experience. Plast Reconstr Surg 2009;124:1429-36.

13. Rawson AE, McClellan WT. Current concepts in breast reconstruction. W V Med J 2009;105:16-22.

14. Nava MB, Bonavita M, Arioli N. Oncoplastic and reconstructive surgery of the breast. London: Taylor \& Francis 2004:204.

15. Collis N, Sharpe DT. Breast reconstruction by tissue expansion. A retrospective technical review of 197 two-stage delayed reconstructions following mastectomy for malignant breast disease in 189 patients. Br J Plast Surg 2000;53:37-41.

16. Foo ITH, Coleman DJ, Holmes JD, Palmer JH, Sharpe DT. Delay between expansion and expander/implant exchange in breast reconstruction - a prospective study. Br J Plast Surg 1992;45:279-83.

17. Cordeiro PG, McCarthy CM. A single surgeon's 12-year experience with tissue expander/implant breast reconstruction: Part II. An analysis of longterm complications, aesthetic outcomes, and patient satisfaction. Plast Reconstr Surg 2006;118:832-9.

18. Nava MB, Spano A, Cadenelli P, et al. Extra-projected implants as an alternative surgical model for breast reconstruction. Implantation strategy and early results. Breast 2008;17:361-6.

19. Abramo AC, De Oliveira VR, Ledo-Silva MC, De Oliveira EL. How texture-inducing contraction vectors affect the fibrous capsule shrinkage around breasts implants? Aesthetic Plast Surg 2010;34:555-60.
20. Gahm J, Edsander-Nord A, Jurell G, Wickman M. No differences in aesthetic outcome or patient satisfaction between anatomically shaped and round expandable implants in bilateral breast reconstructions: A randomized study. Plast Reconstr Surg 2010;126:1419-27.

21. Taylor CW, Horgan K, Dodwell D. Oncological aspects of breast reconstruction. Breast 2005;14:118-30.

22. Macadam SA, Clugston PA, Germann ET. Retrospective case review of capsular contracture after two-stage breast reconstruction: Is colonization of the tissue expander pocket associated with subsequent implant capsular contracture? Ann Plast Surg 2004;53:420-4.

23. Mitchem J, Herrmann D, Margenthaler JA, Aft RL. Impact of neoadjuvant chemotherapy on rate of tissue expander/implant loss and progression to successful breast reconstruction following mastectomy. Am J Surg 2008;196:519-22.

24. Francis SH, Ruberg RL, Stevenson KB, et al. Independent risk factors for infection in tissue expander breast reconstruction. Plast Reconstr Surg 2009;124:1790-6.

25. Contant CME, van Geel AN, Van der Holt B, Griep C, Tjong JWR, Wiggers T. Morbidity of immediate breast reconstruction (IBR) after mastectomy by a subpectorally placed silicone prosthesis: The adverse effect of radiotherapy. Eur J Surg Oncol 2000;26:344-50.

26. Giacalone PL, Rathat G, Daures JP, et al. New concept for immediate breast reconstruction for invasive cancers: Feasibility, oncological safety and esthetic outcome of post-neoadjuvant therapy immediate breast reconstruction versus delayed breast reconstruction: A prospective pilot study. Breast Cancer Res Treat 2010;122:439-51.

27. Goodwin SJ, McCarthy CM, Pusic AL. Complications in smokers after postmastectomy tissue expander/implant breast reconstruction. Ann Plast Surg 2005;55:16-9.

28. Roostaeian J, Crisera C. Current options in breast reconstruction with or without radiotherapy. Curr Opin Obstet Gynecol 2011;23:44-50.

29. Ragaz J, Jackson SM, Le N. Adjuvant radiotherapy and chemotherapy in node-positive premenopausal women with breast cancer. N Engl J Med 1997;337:956-62.

30. Recht A, Edge SB, Solin LJ. Postmastectomy radiotherapy: Guidelines of the American Society of Clinical Oncology. J Clin Oncol 2001;19:1539-69.

31. Percec I, Bucky LP. Successful prosthetic breast reconstruction after radiation therapy. Ann Plast Surg 2008;60:527-31.

32. Ananthakrishnan P, Lucas A. Options and considerations in the timing of breast reconstruction after mastectomy. Cleve Clin J Med 2008;75(Suppl 1):S30-3.

33. Pomahac B, Recht A, May JW Jr, Hergrueter CA, Slavin SA. New trends in breast cancer management. Is the era of immediate breast reconstruction changing? Ann Surg 2006;244:282-8.

34. Roje Z, Roje Z, Jankovic S, Ninkovic M. Breast reconstruction after mastectomy. Coll Antropol 2010;34(Suppl 1):113-23.

35. Parsa AA, Jackowe DJ, Johnson EW. Selection criteria for expander/implant breast reconstruction following radiation therapy. Hawaii Med J 2009;68:66-8.

36. Kronowitz SJ, Robb GL. Radiation therapy and breast reconstruction: A critical review of the literature. Plast Reconstr Surg 2009; $124: 395-408$. 